\title{
EGFR and ERK activation resists flavonoid quercetin-induced anticancer activities in human cervical cancer cells in vitro
}

\author{
XIN CHEN $^{1}$, PENGLI XU ${ }^{2}$, HUIJUN ZHANG ${ }^{3}$, XIAOSAN SU $^{4}$, LIHUA GUO $^{5}$, XUHONG ZHOU $^{4}$, \\ JUNLIANG WANG ${ }^{4}$, PENG HUANG $^{6}$, QINGZHI ZHANG ${ }^{1}$ and RUIFEN SUN ${ }^{4}$ \\ ${ }^{1}$ Molecular Biology Laboratory, Yunnan University of Chinese Medicine, Kunming, Yunnan 650500; \\ ${ }^{2}$ Collaborative Innovation Center, Henan University of Chinese Medicine, Zhengzhou, Henan 450000; \\ ${ }^{3}$ Department of Cardiothoracic Surgery, Huashan Hospital of Fudan University, Shanghai 200030; \\ ${ }^{4}$ Research and Experiment Center, Yunnan University of Chinese Traditional Medicine, Kunming, \\ Yunnan 650500; ${ }^{5}$ Department of Oncology, Yunnan Provincial Hospital of Chinese Medicine, \\ Kunming, Yunnan 650500, P.R. China; ${ }^{6}$ Department of Urology, Okayama University Graduate \\ School of Medicine, Dentistry and Pharmaceutical Sciences, Tokyo 163-8001, Japan
}

Received April 11,2021; Accepted June 28, 2021

DOI: 10.3892/ol.2021.13015

\begin{abstract}
In the present study, due to the complex and numerous targets of Sarcandrae Herb (also known as Zhong Jie Feng), network pharmacology was performed to analyze its therapeutic effect on 2 cervical cancer cell lines, which could assist with the development of novel therapies. The results suggested that the natural flavonoid quercetin (Que), the effective antitumor ingredient in SH, which is widely present in a variety of plants, may depend on the target, EGFR. Previous studies have shown that EGFR serves a crucial role in the occurrence and development of cervical cancer, but its downstream molecules and regulatory mechanisms remain unknown. The anti-cervical cancer cell properties of Que, which are present in ubiquitous plants, were examined in vitro to identify the association between Que and its underlying pathway using MTT assays, flow cytometry, western blot analysis and Transwell assays. It was found that Que reduced cervical cancer cell viability, promoted $\mathrm{G}_{2} / \mathrm{M}$ phase cell cycle arrest and cell apoptosis, as well as inhibited cell migration and invasion. The Tyr1068 phosphorylation site of EGFR and the corresponding ERK target were also examined and the 2 kinases were markedly activated by
\end{abstract}

Correspondence to: Dr Ruifen Sun, Research and Experiment Center, Yunnan University of Chinese Traditional Medicine, 1076 Yuhua Road, Chenggong, Kunming, Yunnan 650500, P.R. China

E-mail: sunruifen@ynutcm.edu.cn

Ms. Qingzhi Zhang, Molecular Biology Laboratory, Yunnan University of Chinese Medicine, 1076 Yuhua Road, Chenggong, Kunming, Yunnan 650500, P.R. China

E-mail: zhangqingzhi@ynutcm.edu.cn

Key words: quercetin, EGFR, ERK, cervical cancer, negative regulatory association
Que. Furthermore, the EGFR inhibitor, afatinib and the ERK inhibitor, U0126 blocked the increase of EGFR and ERK phosphorylation, and resulted in a notable enhancement of apoptosis and cell cycle arrest. Therefore, to the best of our knowledge, the current results provided the first evidence that EGFR and ERK activation induced by Que could resist Que-induced anticancer activities. On this basis, the present study determined the role of EGFR and the underlying signaling pathways involved in the anti-cervical cancer malignant behavior induced by Que and identified the negative regulatory association.

\section{Introduction}

Globally, as of 2017, 500,000 women were, and 288,000 patients died from cervical cancer (1). In addition, there are $\sim 135,000$ new cases in China each year, accounting for $1 / 3$ of the global incidence rate $(2,3)$. Cervical cancer is highly malignant, progresses quickly and has a poor prognosis. Furthermore, its occurrence is affected by genetic and environmental factors (4). The main treatment is radiotherapy, chemotherapy and surgery; therefore, it is important to develop novel drugs, as well as diagnostic and prognostic markers (5).

Traditional Chinese Medicine (TCM) serves an increasingly important role in the comprehensive treatment of cervical cancer, and may be a new direction for the prevention and treatment of this disease in the future (6). Qian et al (7) reported that Erhuang powder had significant clinical effects in the treatment of high-risk human papillomavirus (HPV) infection with mild cervical epithelial neoplasia and moderate cervical epithelial neoplasia. At the same time, the serum concentrations of IFN- $\gamma$ and TNF- $\alpha$ in patients with cervical cancer were increased, and IL-4 and IL-10 concentrations were reduced. Furthermore, Chen et al (8) revealed that the Houttuynia cordata decoction could effectively increase the HPV negative rate of cervical intraepithelial neoplasia.

Sarcandra Herb (SH) is an integral component of Castanea mollissima named grass coral in China, with an apparent thera- 
peutic effect (9), has become a highly researched Chinese herbal medicine due to its significant clinical effects, and its main method of use includes Zhong Jie Feng injection and grass coral lozenges (10). Several monomers in SH, showing significant research value, have been analyzed and screened using network pharmacology. Researchers in China have previously reported that the caffeic acid, 3,4-dihydroxyphenethyl ester monomer, isolated and extracted from $\mathrm{SH}$, could selectively activate the phosphorylation of p38 and ERK1/2, in the MAPK signaling pathway, in cervical cancer cells, and could promote apoptosis and autophagy (11). In addition, Trusov et al (12) examined the effect of the natural flavonoid, quercetin (Que), found in $\mathrm{SH}$, on tumor growth inhibition and the prolongation of the survival time in C-57 mice. These authors identified that Que had an inhibitory rate of 20.7-60.1\% on the solid tumors from the mouse liver cancer cell line, S180, and a $36.8 \%$ survival time extension rate for the $\mathrm{S} 180$ ascites model.

The aim of the present study was to investigate the antitumor activity of SH to identify the target that plays a role in the biological functions of cervical cancer cells, and analyze the positive and negative regulatory effects.

\section{Materials and methods}

Reagents and antibodies. Que was purchased from Sigma Aldrich (Merck KGaA). The following primary antibodies were used in the present study: phosphorylated (p)-EGFR (Tyr1068) (1:1,000; cat. no. 3777; Cell Signaling Technology, Inc.), p-MEK (1:1,000; cat. no. 2338; Cell Signaling Technology, Inc.), p-cell division cycle (Cdc) 42 (1:1,000; cat. no. 2461; Cell Signaling Technology, Inc.), EGFR (1:1,000; cat. no. 4267; Cell Signaling Technology, Inc.), MEK (1:1,000; cat. no. 9122; Cell Signaling Technology, Inc.), p-44/42 MAPK (ERK1/2) (1:1,000; cat. no. 4370; Cell Signaling Technology, Inc.), caspase-3 (1:1,000; cat. no. 9664; Cell Signaling Technology, Inc.), GAPDH (1:3,000; cat. no. 5174; Cell Signaling Technology, Inc.), $\beta$-tubulin $(1: 3,000$; cat. no. 10094-1-AP; ProteinTech Group, Inc.), cdc42 (1:1,000; cat. no. 10155-1-AP; ProteinTech Group, Inc.), Bax (1:1,000; cat. no. 50599-2-lg; ProteinTech Group, Inc.) and Bcl-2 (1:1,000; cat. no. 12789-1-AP; ProteinTech Group, Inc.). The secondary antibodies, HRP-conjugated goat-anti-rabbit (cat. no. L3012) and goat-anti-mouse (cat. no. L3032) IgG were purchased from Signalway Antibody LLC. The small molecule inhibitors, aftinib, PD98059, U0126, ML141 for EGFR, MEK, ERK and Cdc42 were purchased from MedChemExpress.

Cell culture. The human cervical cancer cell lines (HeLa and $\mathrm{SiHa}$ ) were purchased from Shanghai Zhongqiao Xinzhou Biological Technology Co., Ltd., and were cultured in RPIM1640 medium (Biological Industries), supplemented with 10\% FBS (Biological Industries), 100 units of penicillin and $100 \mu \mathrm{g} /$ $\mathrm{ml}$ streptomycin at $37^{\circ} \mathrm{C}$ in a humidified incubator with $5 \% \mathrm{CO}_{2}$.

Public data collection. Prediction and screening of the anti-cervical cancer effects and disease targets of SH ingredients from TCM systems pharmacology database and analysis platform (TCMSP), GeneCards and OMIM databases were conducted. The chemical compositions and genes associated with SH in 3 separate databases were searched: i) TCMSP (http://
ibts.hkbu.edu.hk/LSP/tcmsp.php), oral bioavailability was set to $>30 \%$ and drug-likeness was set to $>0.18$, to obtain the chemical composition of $\mathrm{SH}$; ii) the molecular structure was confirmed using PubChem (https://pubchem.ncbi.nlm.nih.gov/), the targets associated with the effective components of SH could also be exported in batches in TCMSP; and iii) the UniProt database (http://www.uniprot.org/uniprot/) ID number was downloaded to convert the entire documents using Perl codes, then, the association between drug and disease was evaluated.

Screening of key words (cervical cancer) was performed to obtain related targets in the GeneCards (http://www. genecards.org/) and OMIM databases (http://www.ncbi.nlm. nih.gov/omim) by eliminating duplicate and pseudo-positive genes. These were then matched with potential targets for the anti-cervical cancer effect and the common targets were presented as a Venn diagram. The Protein Analysis by Evolutionary Relationship database (PANTHER; v11; http:// pantherdb.org) contains comprehensive information on the evolution and function of protein-coding genes from 104 complete sequenced genomes. The PANTHER software tool allows users to classify new protein sequences and analyze gene lists obtained from large-scale genome experiments. The Search Tool for the Retrieval of Interacting Genes/Proteins database (https://string.db.org/) contains known and predicted protein-protein interactions. Thus, the protein interactions in tab-separated values format were obtained. Cytoscape3.7.1 (http://www.cytoscape.org/) software was used to generate the Zhong Jie Feng-Target network diagram. Nodes-1 and -2, and the combined score information in the files were inputted into Cytoscape to create the interaction network; the style option from the statistics tool (Cytoscape $>$ Tools $>$ Network $>$ Analyz er $>$ Analysis $>$ Generate) was used to apply the node size and color settings to reflect the combination degree. R software (v.3.7.1; https://cran.r-project.org/bin/windows/base/) (13) was used for bioinformatics analysis.

Staining using 5-Ethynyl-2'-deoxyuridine (EdU). The detailed steps of the experiment were conducted according to the manufacturer's instructions (Guangzhou RiboBio Co., Ltd.). Approximately, 10,000 cells/per well in logarithmic growth phase were seeded in a 48 -well plate, cultured to the normal growth stage, then Que $(40 \mu \mathrm{M})$ was added after $8 \mathrm{~h}$. EdU solution was diluted in complete medium at a ratio of 1,000:1 in $200 \mu \mathrm{l}$, then added to each well and the cells were incubated for $2 \mathrm{~h}$, then washed with PBS twice, for $5 \mathrm{~min}$ each time. Subsequently, $100 \mu \mathrm{l}$ PBS, containing 4\% paraformaldehyde, was added to each well, then the cells were incubated at room temperature for $30 \mathrm{~min}$ and $200 \mu 12 \mathrm{mg} / \mathrm{ml}$ glycine solution was added. The cells were incubated for $5 \mathrm{~min}$ on a shaker, following which $200 \mu \mathrm{l}$ PBS was added to wash the cells, then $200 \mu 10.5 \%$ TritonX-100 was added to each well and incubated at room temperature on a shaker for $10 \mathrm{~min}$. Next, the cells were washed with PBS once for $5 \mathrm{~min}$, then $100 \mu \mathrm{l}$ 1X Apollo staining reaction solution was added to each well, and the cells were incubated at room temperature for $30 \mathrm{~min}$ then the solution was discarded. Subsequently, the cells were washed with $200 \mu \mathrm{l} 0.5 \%$ TritonX-100 twice for $10 \mathrm{~min}$ each time, then $200 \mu \mathrm{l} 1 \mathrm{X}$ Hoechst 33342 reaction solution (diluted with deionized water at ratio 100:1) was added to each well and the cells were incubated at room temperature for $30 \mathrm{~min}$ in 
a shaker. Lastly, the cells were washed with $200 \mu 1$ PBS twice and the images were captured using a fluorescence microscope (x40; Axio Scope.A1; Zeiss AG). The red signal that was observed indicated a positive signal and lower levels indicated that the cell proliferation ability was lower.

MTT assay. Logarithmic growth phase cells were seeded in a 96-well plate, in triplicate, at a density of $5 \times 10^{3} /$ well (the edge holes were filled with sterile PBS). Different concentrations of Que $(0,20,40,60,80,100,120,160$ and $200 \mu \mathrm{M})$ were used to treat the cells for 24,48 and $72 \mathrm{~h}$, MTT solution $(0.5 \mathrm{mg} / \mathrm{ml}$; $0.05 \%$ MTT) was added to each well and the culture was continued for $4 \mathrm{~h}$. Then, $150 \mu \mathrm{l}$ dimethyl sulfoxide was added and the plate was placed on a shaker at low speed for $10 \mathrm{~min}$ to fully dissolve the crystals. The absorbance was measured at $490 \mathrm{~nm}$ and the $\mathrm{IC}_{50}$ was calculated using SPSS software (v20.0; IBM Corp.).

The inhibitors, afatinib $(2 \mu \mathrm{M})$ and $\mathrm{U} 0126(10 \mu \mathrm{M})$ were also used to measure cell viability and added to the cells $2 \mathrm{~h}$ before the cells were then treated with Que for $24 \mathrm{~h}$.

Detection of cell cycle. The cells were treated with Que $(120 \mu \mathrm{M})$ for $8 \mathrm{~h}$, then digested and resuspended using $1 \mathrm{ml}$ pre-chilled $70 \%$ alcohol, administered drop by drop. After fixing overnight at $-20^{\circ} \mathrm{C}$, the samples were centrifuged at 3,000 $\mathrm{x}$ g for $5 \mathrm{~min}$ at $4^{\circ} \mathrm{C}$ to remove the ethanol. Then, $5 \mu \mathrm{l}$ RNase was added and the samples were incubated in a $37^{\circ} \mathrm{C}$ water bath for $30 \mathrm{~min}$, following which $100 \mu \mathrm{l} 1 \mathrm{X}$ binding buffer and $5 \mu \mathrm{l}$ PI staining solution (Becton, Dickinson and Company) were added into each sample and incubated at room temperature for $15 \mathrm{~min}$ in the dark. Subsequently, the cell cycle was detected using a flow cytometer (BD FACS Calibur; Becton, Dickinson and Company) and analyzed using FlowJo software (v10; Tree Star, Inc.).

Wound healing assay. The HeLa and SiHa cells were seeded into a 6-well culture plate with horizontal straight lines at the bottom, at a density of $5 \times 10^{6}$ cells $/ \mathrm{ml}$ per hole. The cells were gently scratched according to the middle line using a pipette tip after $24 \mathrm{~h}$. Then, the plate was washed with PBS to remove cell debris, then cultured again for 24 and $36 \mathrm{~h}$. At the beginning, the degree of confluence at $0 \mathrm{~h}$ time point on both sides of the wound was checked using a microscope (x40; Axio Scope.A1; Zeiss AG) and was $80-100 \%$. Images of all the groups at 0,24 and $36 \mathrm{~h}$ were captured, and the wound healing difference after Que administration at the indicated concentration $(0$ and $80 \mu \mathrm{M})$ in serum-free RPMI-1640 medium (Biological Industries) were detected. The cell scratch area was used as an index to evaluate the degree of wound healing and was analyzed using ImageJ software (v1.8.0.112; National Institutes of Health).

Transwell assay. For the migration assay, the HeLa and SiHa cells, in the log-phase, at a density of $5 \times 10^{4}$ cells $/ \mathrm{ml}$, were added to the upper chamber, in a $200 \mu \mathrm{l}$ suspension diluted with 1\% FBS-containing RPMI-1640 medium (Biological Industries). Next, $600 \mu 1$ RPMI-1640 culture medium, containing $10 \%$ serum, was added to the lower chamber for a $24 \mathrm{~h}$ incubation. Each group had 2 replicates. For the invasion assay, Matrigel was dissolved overnight at $4^{\circ} \mathrm{C}$ and diluted with basic culture medium at a volume ratio of 1:7. Then, $20 \mu$ l Matrigel was placed on the Transwell chamber in a sterile 24 -well plate at $37^{\circ} \mathrm{C}$ for $30 \mathrm{~min}$. The subsequent methods used were performed according to the same protocol as the cell migration assay. After the Matrigel solidified, the non-migrated/invaded cells on the membrane were removed using a cotton swab and PBS. The cells were fixed with $4 \%$ paraformaldehyde solution at room temperature for $10 \mathrm{~min}$, then stained with crystal violet at room temperature for $5 \mathrm{~min}$. The number of migrated and invaded cells, and the average value for each sample were observed and calculated using a light microscope (x40; Axiolab 5; Zeiss AG).

Annexin V-PE/7-AAD double-staining assay. Cell apoptosis was detected using a double staining Annexin V-PE/7-AAD (BD Biosciences) method. The cells were treated with Que $(0,40,80$ and $120 \mu \mathrm{M})$ for $24 \mathrm{~h}$, then digested with trypsin, without EDTA and rinsed with sterile $1 \mathrm{X}$ binding buffer, diluted with PBS. The cells were subsequently incubated at room temperature for $10 \mathrm{~min}$ in the dark with $5 \mu \mathrm{l}$ Annexin V-PE and $5 \mu \mathrm{l}$ 7-AAD. FACS flow cytometry (BD FACS Calibur; Becton, Dickinson and Company) was performed to detect apoptosis and the data were analyzed using FlowJo software (v10; FlowJo LLC). The number of cells in the upper right and the lower right quadrants of the flow cytometry plots represent the proportion of late and early apoptotic cells respectively, and the sum of the two represents the proportion of cervical cancer cells undergoing apoptosis.

Western blot analysis. RIPA (Beijing Solarbio Science and Technology Co., Ltd.) was used to extract the total protein from the cells and the BCA method was used for sample concentration determination. In total, $\sim 20 \mu \mathrm{g}$ total protein was used for separation using 8-12\% SDS-PAGE, following which the separated protein was electro-transferred to a PVDF membrane, and the primary antibody was added and incubated overnight at $4{ }^{\circ} \mathrm{C}$ after blocking with $5 \%$ skimmed milk at room temperature for $1 \mathrm{~h}$. The membranes were washed 3 times with 1X TBS-Tween-20 (at a ratio of 1,000:1), for $10 \mathrm{~min}$ each time, then the membranes were incubated for $2 \mathrm{~h}$ with the corresponding secondary antibody $(1: 3,000)$ at room temperature. The expression of each target protein was detected using an ECL reagent (EMD Millipore) and a multifunctional molecular gel imaging system.

The following inhibitors, afatinib $(2 \mu \mathrm{M}), \mathrm{U} 0126(10 \mu \mathrm{M})$, PD98059 $(5 \mu \mathrm{M})$ and ML141 $(10 \mu \mathrm{M})$ were added to the cells $2 \mathrm{~h}$ before the cells were then treated with Que for $8 \mathrm{~h}$ at different combinations, to also measure protein expression. Each experiment was repeated at least 3 times and the representative results are presented.

Statistical analysis. GraphPad Prism v8.0 software (GraphPad Software, Inc.) was used to analyze the data. One-way ANOVA followed by Tukey's post hoc test or unpaired Student's t-test were used to evaluate the statistical differences between $>2$ or 2 groups, respectively. $\mathrm{P}<0.05$ was considered to indicate a statistically significant difference.

\section{Results}

Que in SH targets EGFR. There were 92 targets predicted by TCMSP, for the active ingredients of $\mathrm{SH}$, and a total of 

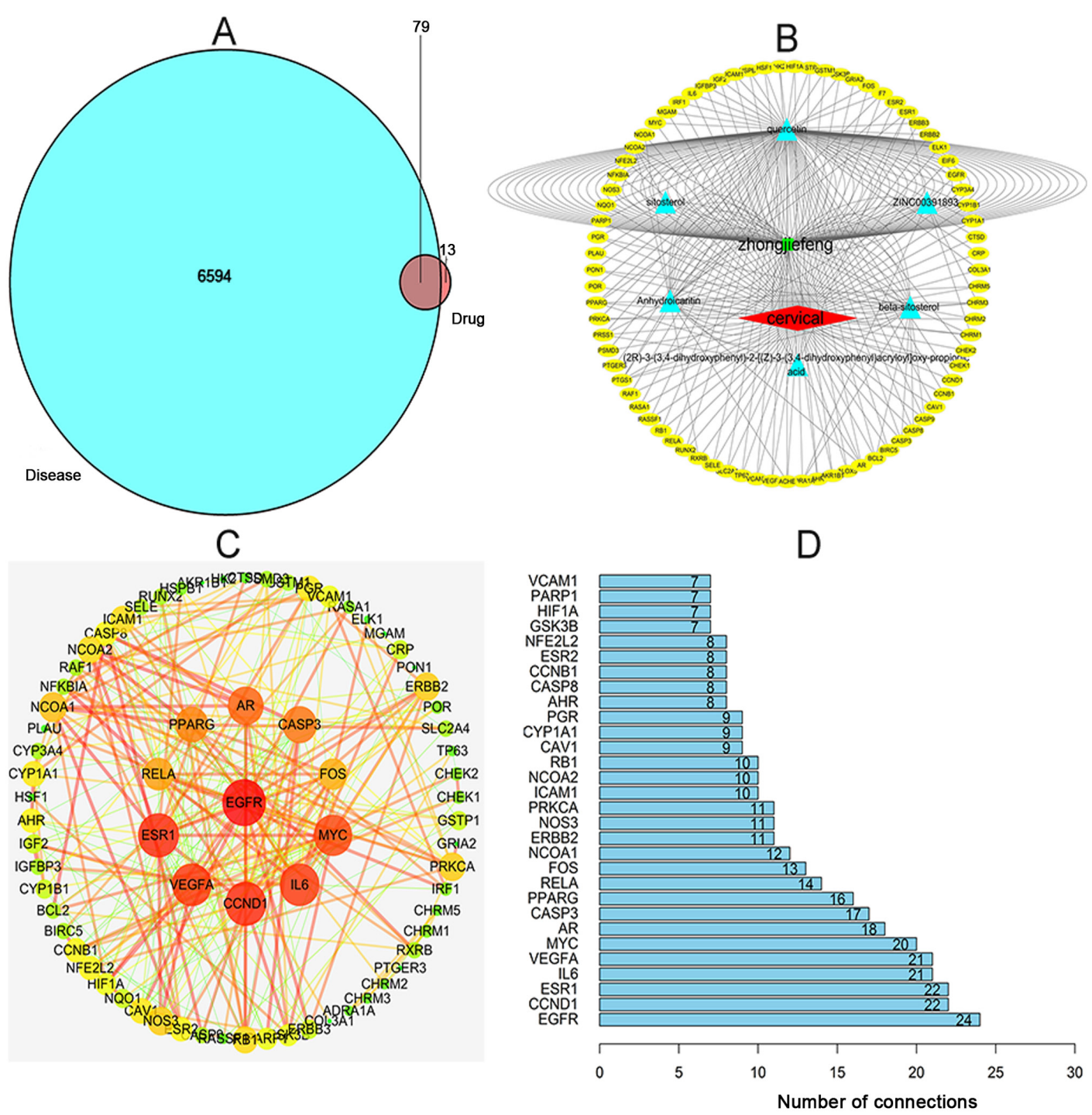

Figure 1. Quercetin in Sarcandrae Herb targets EGFR. (A) A total of 92 targets were predicted by Traditional Chinese Medicine systems pharmacology database and analysis platform and 6,673 targets, associated with cervical cancer, were searched in the disease databases, from which 79 common targets were screened using R software. (B) A network diagram revealing the drug component-target-disease relationship. (C) The size, color and number of the nodes reflect the strength of the relationship. (D) how many other nodes are associated with each node, reflecting the importance of this node.

6,673 targets, associated with cervical cancer, were searched in the GeneCards and OMIM databases. In addition, the total number of drug-related targets was 92 , with 79 common targets following the intersection with disease-related targets. The drug component-target-disease relationship network diagram was established using R software (Fig. 1A and B). The yellow ellipse represents common targets of cervical cancer and the drug, while the blue triangles represent the active ingredients of SH. The same targets, corresponding to different effective ingredients, are presented in Fig. 1B, which shows the characteristics of the multi-components and multi-targets of TCM. It can also be seen that Que has an intersection with almost every target, which proves that it has strong research value (Fig. 1B). In Fig. 1C, the color and thickness of the lines represent the strength of the association and the final functional protein network diagram is presented. The obtained network revealed the node, EGFR as the hub gene, suggesting that it may have important biological significance in $\mathrm{SH}$-induced anticancer effects in cervical cancer cell lines (Fig. 1C and D).
Que reduces cell viability. To determine the cytotoxic effect of Que on the human cervical cancer cell lines, the cells were treated with increasing concentrations of Que for 24, 48 and $72 \mathrm{~h}$, then a MTT assay was performed to measure cell viability. The $\mathrm{IC}_{50}$ of $\mathrm{SiHa}$ and HeLa cells at the three time points was $150.21,112.06$ and $83.3 \mu \mathrm{M}$, and 132.12, 95.25 and $70.12 \mu \mathrm{M}$, respectively (Fig. 2A). Consistently, the EdU staining results also suggested that Que inhibited the proliferation and division of the cervical cancer cells (Fig. 2B).

Que induces $G_{2} / M$ arrest. Next, it was investigated whether Que was associated with the cell cycle of the cervical cancer cells. The HeLa and SiHa cell lines were treated with Que for $8 \mathrm{~h}$, following which flow cytometry was performed. The results demonstrated that Que significantly increased the percentage of $\mathrm{SiHa}$ and HeLa cells in the $\mathrm{G}_{2} / \mathrm{M}$ phase. It was found that the percentages of $\mathrm{G}_{2} / \mathrm{M}$ cells were 29.3 and $62.3 \%$ for the $\mathrm{SiHa}$ cells and 29.7 and $54.7 \%$ for the HeLa cells, at 

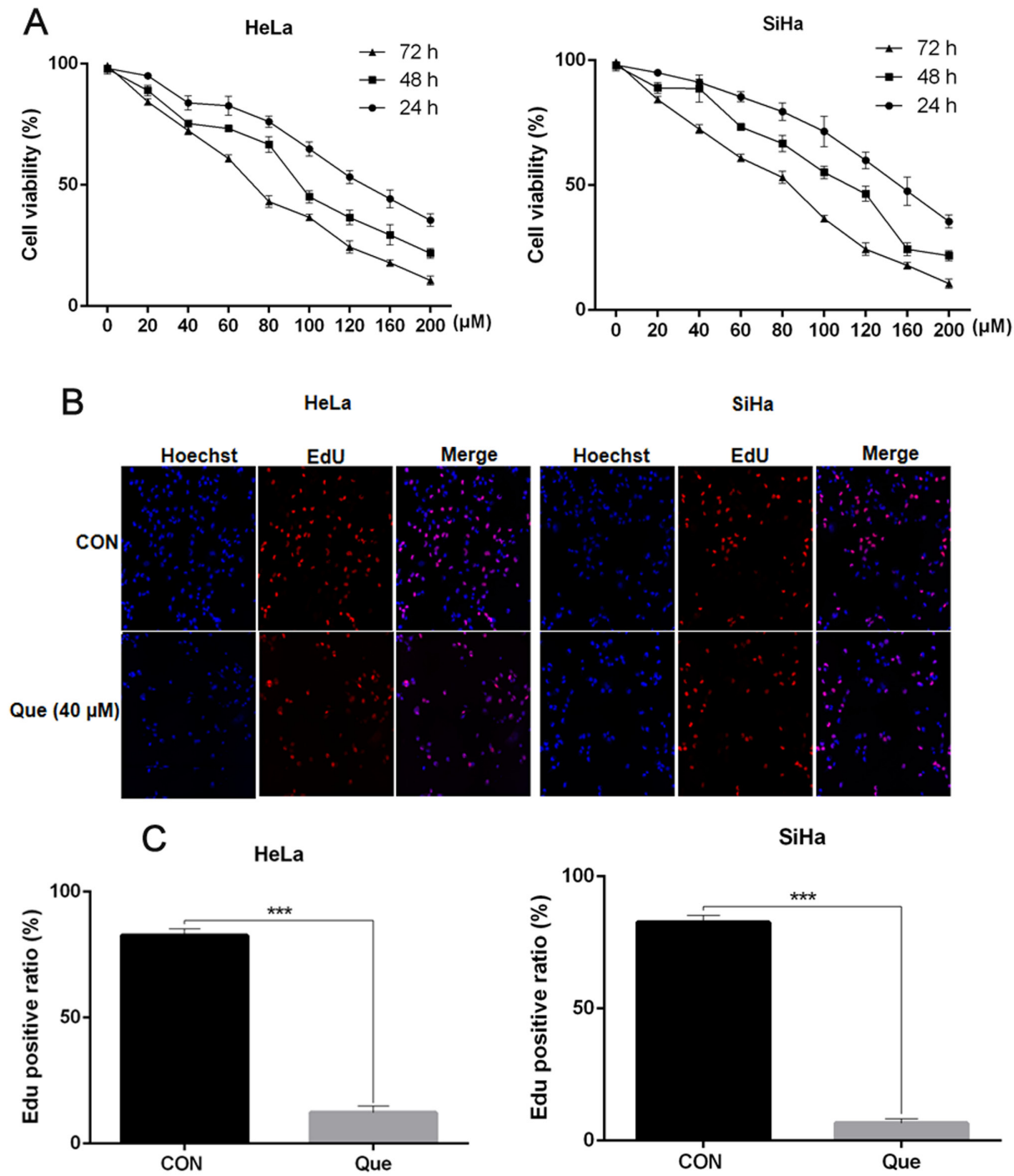

Figure 2. Que suppresses the viability of cervical cancer cell lines. (A) The SiHa and HeLa cell lines were treated with the indicated concentrations of Que for 24,48 and $72 \mathrm{~h}$, then the cell viability was measured using a MTT assay. (B) The cervical cancer cells were treated with $40 \mu \mathrm{M}$ Que for $8 \mathrm{~h}$, then EdU staining was performed and the results were (C) statistically analyzed. ${ }^{* * *} \mathrm{P}<0.001$. EdU, 5-ethynyl-2'-deoxyuridine; Que, quercetin; CON control.

0 and $120 \mu \mathrm{M}$, respectively (Fig. 3A-D), indicating that Que induced $\mathrm{G}_{2} / \mathrm{M}$ arrest in the cervical cancer cell lines. Western blot analysis revealed that Que caused a decline in p-Cdc42 and p21 protein expression level in a time and concentration-dependent manner, respectively, which served a key role in the regulation of cell cycle (Fig. 3E). Collectively, it was suggested that Que notably blocked the cervical cancer cell cycle in the $\mathrm{G}_{2} / \mathrm{M}$ phase.

Que inhibits cell migration and invasion. A wound healing assay was performed to investigate whether Que inhibited cervical cancer cell migration. It was identified that Que significantly suppressed the wound healing rate of the HeLa and SiHa cells (Fig. 4A). Furthermore, a Transwell assay was conducted to determine whether Que inhibits cervical cancer cell migration and invasion. The number of cells passing through the membrane and Matrigel to the lower chamber was decreased with Que was gradually decreased with increasing Que concentrations (Fig. 4B), suggesting that Que suppressed the migration and invasion of the SiHa and HeLa cells.
Que promotes cervical cancer cell apoptosis. The cells treated with Que for $24 \mathrm{~h}$ presented with the morphological features of apoptosis, including shrinking in size, becoming round, losing connections and breaking away from the surrounding cells (data not shown). Subsequently, Que-induced apoptosis was further evaluated using Annexin V-PE/7-AAD staining. As presented in Fig. 5A, the proportion of cells undergoing apoptosis was gradually enhanced with the increasing Que concentrations compared with that in the control group.

Caspase-3 serves an important role in cell apoptosis and this process can be blocked by Bcl-2 (14). The results demonstrated that Que significantly promoted the activation of caspase-3. Furthermore, Que increased the expression levels of the pro-apoptotic protein, Bax and decreased the expression level of the anti-apoptotic protein, Bcl-2 (Fig. 5C).

EGFR and ERK activation resists Que-induced cytotoxicity in cervical cancer cells. According to the results of network pharmacology, EGFR may be associated with the Que-induced anticancer effects in cervical cancer. The results indicated that 
A
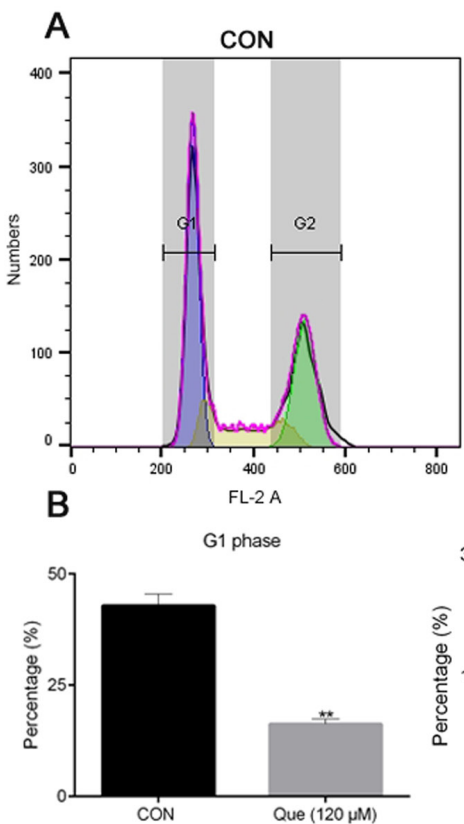

C

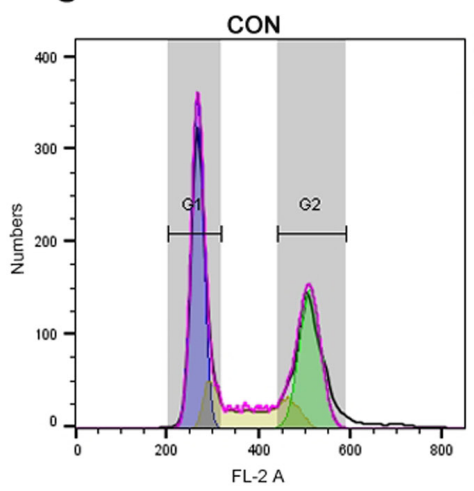

D
HeLa \%Gl : 43.6
\%S : 22.2
\%G2 : 29.7

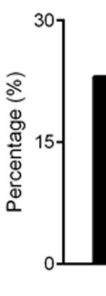

CON

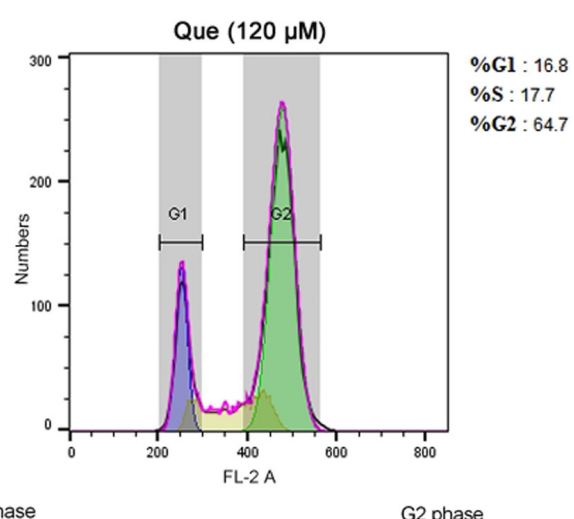

S phase

G2 phase

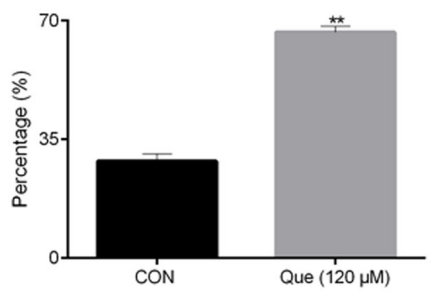

Que $(120 \mu \mathrm{M})$

$\mathrm{SiHa}$

$\% \mathrm{Gl}: 40.6$

$\% \mathrm{~S}: 21.3$

\%G2 : 29.3

G1 phase

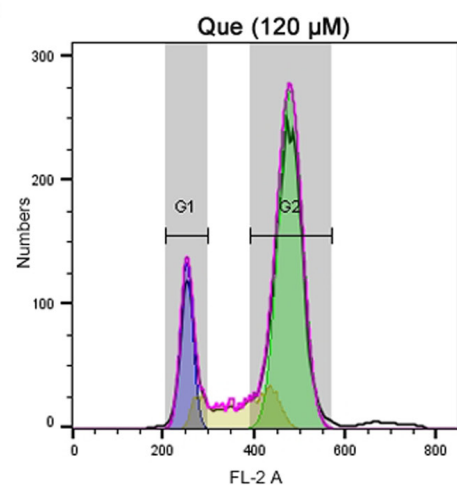

\%Gl : 15.8

$\% \mathrm{~S}: 17.2$

\%G2 : 62.3
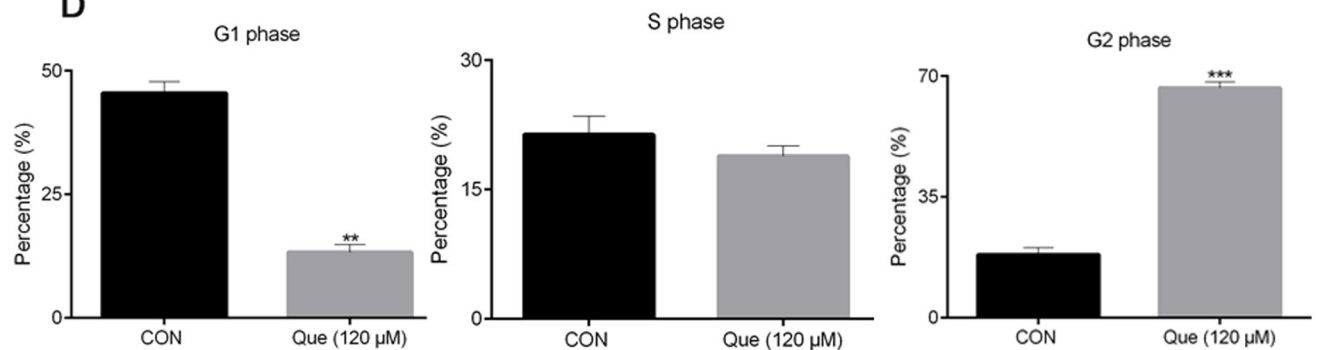

$\mathrm{E}$

$\mathrm{SiHa}$
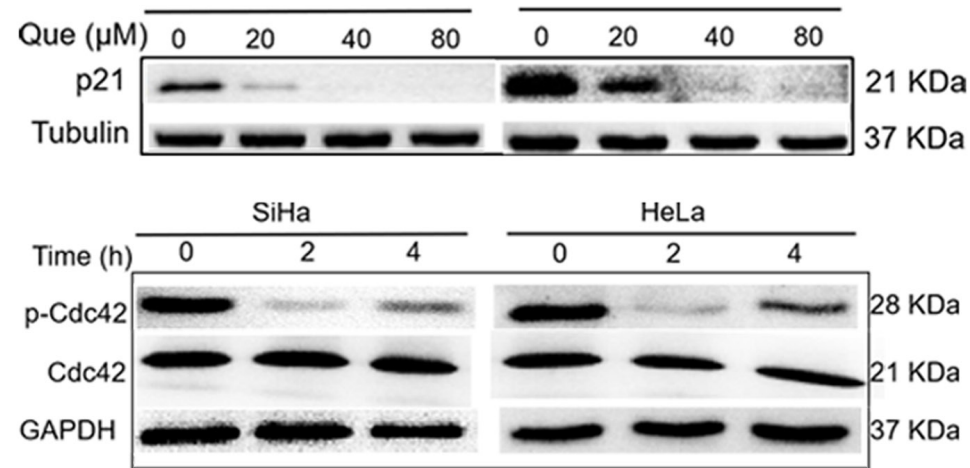

Figure 3. Que promotes cervical cancer cell $\mathrm{G}_{2} / \mathrm{M}$ arrest and affects the expression levels of $\mathrm{G} 1$ phase-related proteins. The (A) HeLa and (C) SiHa cell lines were treated with Que $(0$ and $120 \mu \mathrm{M})$ for $8 \mathrm{~h}$, then flow cytometry analysis was conducted to investigate the cell cycle and (B) and (D) statistically analyzed. (E) The cervical cancer cell lines were treated with Que $(0,40$ and $80 \mu \mathrm{M})$ for $8 \mathrm{~h}$ or Que $(80 \mu \mathrm{M})$ for 0,2 and $4 \mathrm{~h}$, then the protein expression levels were examined using western blot analysis. GAPDH or tubulin were used as the loading control. $n=3 .{ }^{* *} \mathrm{P}<0.01,{ }^{* * * *} \mathrm{P}<0.001$. Que, quercetin; $\mathrm{p}$, phosphorylated; CON, control. 

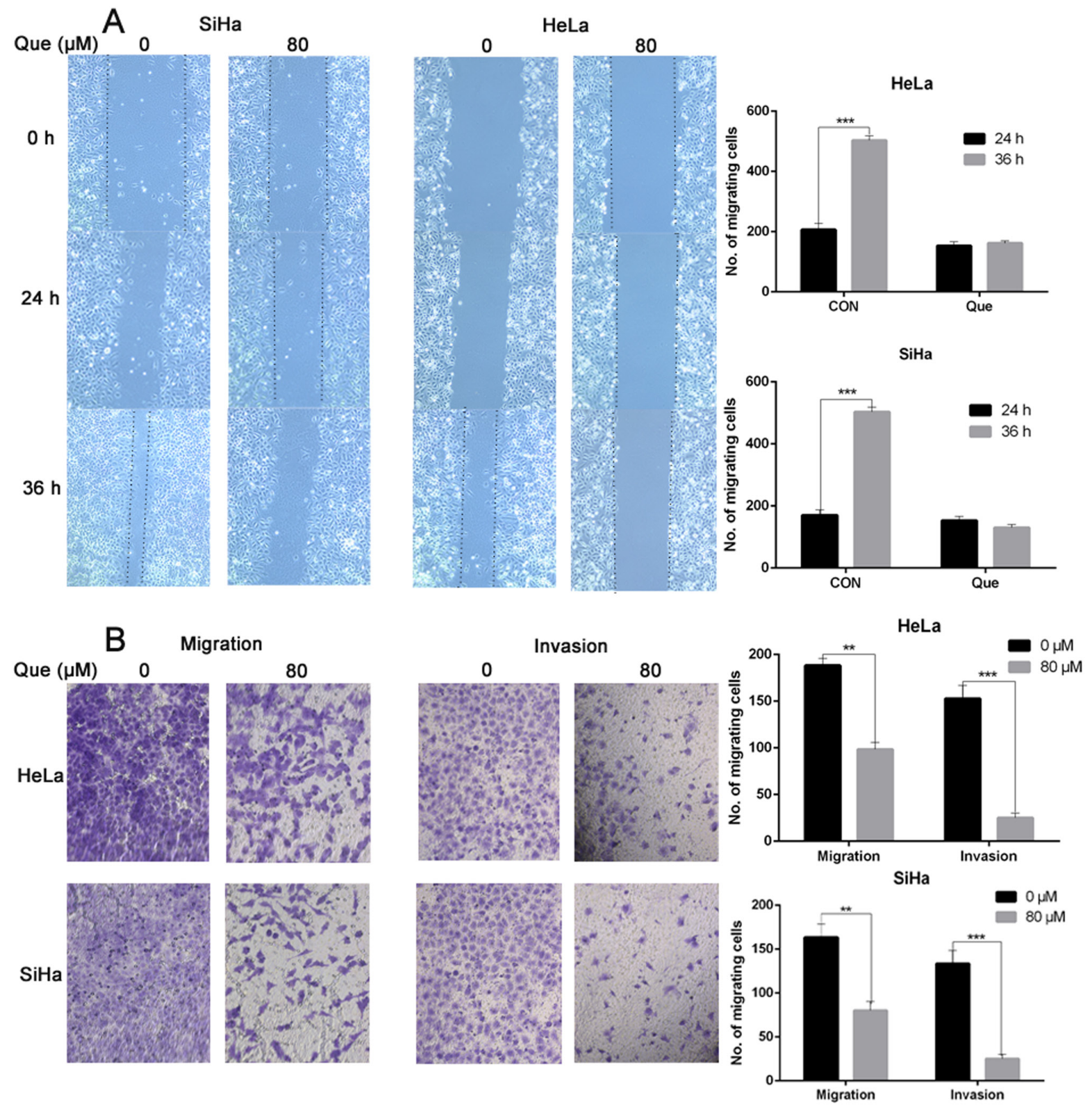

Figure 4. Que inhibits the migration and invasion of the cervical cancer cell lines. (A) The cells were treated with 0 or $80 \mu \mathrm{M}$ Que for 0,24 and $36 \mathrm{~h}$, then the degree of wound healing was measured. (B) In total, $10,000 \mathrm{SiHa}$ and HeLa cells were seeded in the Transwell chamber in $200 \mu 1$ FBS-free medium with the indicated concentration of Que for $48 \mathrm{~h}$. Matrigel was added onto the microporous membrane in advance to simulate the environment of the extracellular matrix was only used for the invasion assay, and then the cells that penetrated the membrane were stained with crystal violet for subsequent examination. $\mathrm{n}=3$. ${ }^{* *} \mathrm{P}<0.01,{ }^{* * *} \mathrm{P}<0.001$. Que, quercetin.

Que markedly increased EGFR activities, but suppressed the activity of Cdc42 (Figs. 6A and 3E, respectively). It has been well-documented that EGFR activation leads to downstream MEK/ERK pathway activation (15). As shown in Fig. 6A, Que notably induced ERK activation, but only marginally affected the activities of MEK1.

To further examine the role of EGFR and ERK in Que-induced anticancer effects, afatinib and U0126 were used to block the activities of EGFR and ERK, respectively. It was found that both afatinib and U0126 effectively inhibited EGFR and ERK activation induced by Que. EGFR is the upstream signal of ERK; therefore, if Que acts on EGFR, then the EGFR inhibitor afatinib will reverse the activation of ERK under the action of quercetin. Unexpectedly, afatinib did not reverse Que-induced ERK activation, indicating that Que may increase ERK activity in an EGFR-independent manner. In addition, PD98059 and ML141 were used to detect the Ras/ Raf/MEK/ERK/MAPK signaling pathway, ML141 further promoted the reduction of Cdc42 protein expression in combination with Que (Fig. 6B).

Next, it was investigated whether EGFR and ERK were associated with Que-induced anticancer activities. It was found that the suppression of EGFR and ERK, using the afatinib and U0126 inhibitors, enhanced Que-induced cell viability inhibition (Fig. 6C), cell cycle arrest and apoptosis (Fig. 7A-D). For example, the apoptotic rate of the HeLa and $\mathrm{SiHa}$ cells with Que alone was 43.3 and $40.71 \%$, respectively, but when afatinib and Que or U0126 and Que were added together, the apoptotic rate increased to 60.92 and $63.4 \%$. The $\mathrm{G}_{2} / \mathrm{M}$ phase ratio in the HeLa and SiHa cells with Que alone 

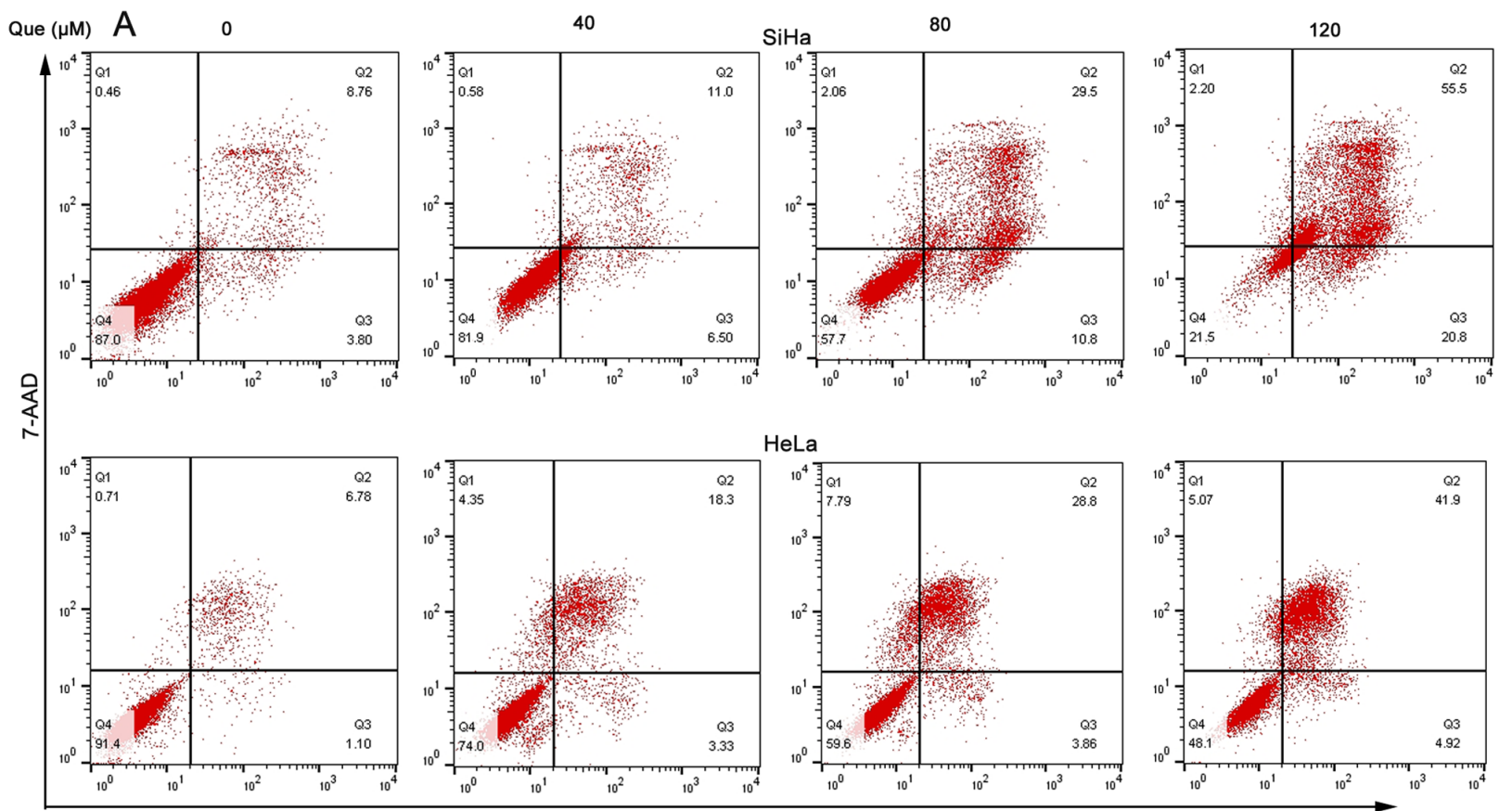

HeLa
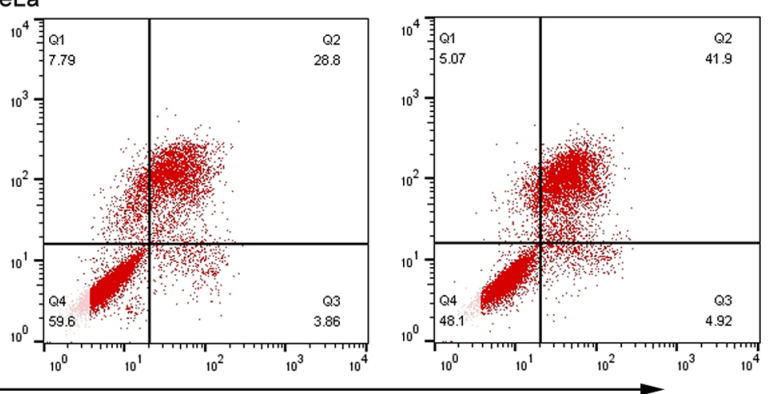

Annexin V-PE

B

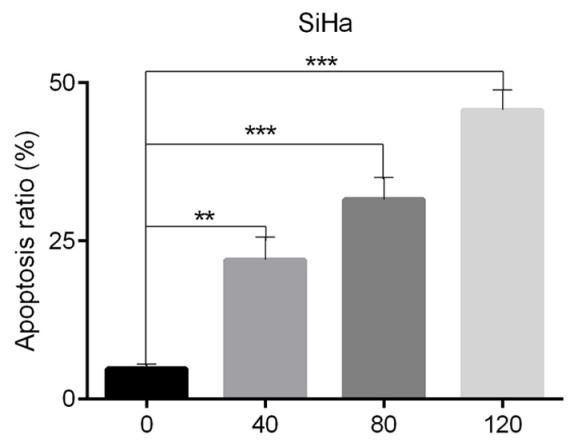

C

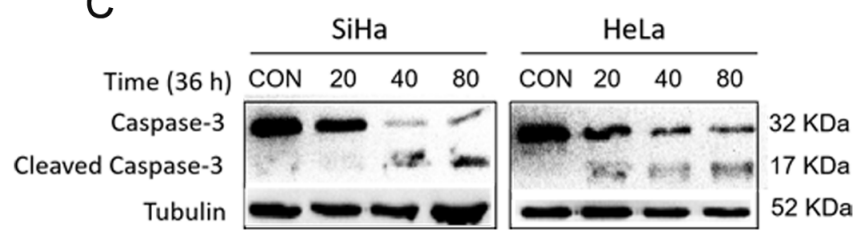

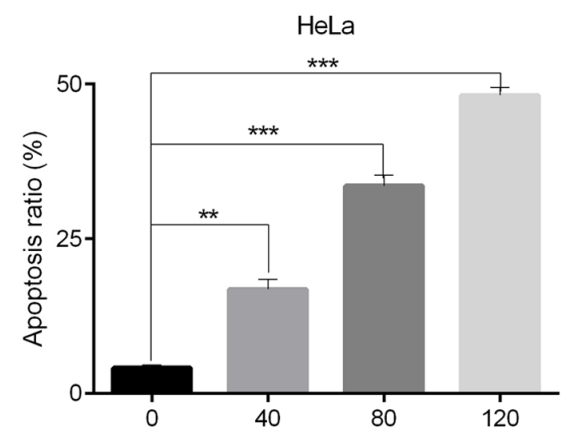
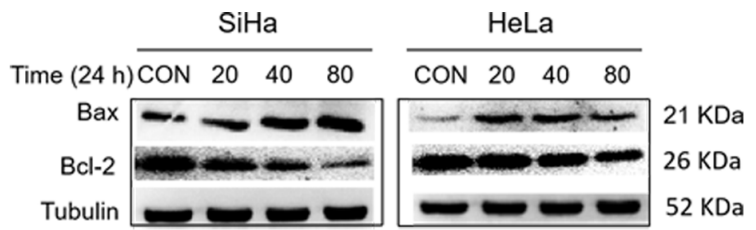

Figure 5. Que promotes cervical cancer cell apoptosis and affects the expression levels of apoptosis-related proteins. (A) The cervical cancer cells were treated with Que $(0,40,80$ and $120 \mu \mathrm{M})$ for $24 \mathrm{~h}$, then flow cytometry analysis was performed to investigate cell apoptosis and the difference was (B) statistically analyzed. (C) The cervical cancer cell lines were treated with Que $(0,20,40$ and $80 \mu \mathrm{M})$ for $36 \mathrm{~h}$, then the protein expression levels were examined using western blot analysis. Tubulin was used as the loading control. $\mathrm{n}=3 .{ }^{* *} \mathrm{P}<0.01,{ }^{* * *} \mathrm{P}<0.001$. Que, quercetin.

was 41.5 and $40.0 \%$, but when U0126 and Que were combined, the ratio increased to 65.6 and $62.4 \%$, respectively suggesting that EGFR and ERK activation had a cytoprotective role in the Que-induced anticancer effects in cervical cancer cell lines.

\section{Discussion}

At present, the morbidity and mortality rates of cervical cancer are at the forefront of malignant tumors, which seriously threatens the health of women (16). In recent years, plant-derived compounds, with the potential to inhibit the development and the proliferation of tumors, have attracted increased attention from scientific researchers (17-19). In the present study, based on network pharmacology, Que is one of the effective ingredients of SH, then the hub gene, EGFR was identified, which could be associated with Que. Que is a natural flavonoid compound, widely present in numerous plants, such as onions, shallots, asparagus, cabbage, mustard greens and green peppers and has a preventive and therapeutic effect on a variety of cancer types, including stomach, breast, liver and cervical cancers (20). Most in vivo and in vitro studies have shown that Que was not carcinogenic (21-23). In 1999, the International Agency for Research on Cancer classified Que as a non-carcinogenic substance to human (24). Phase I and Phase II clinical trials in England have confirmed that Que inhibited the progression of a variety of tumors, and it has 
A
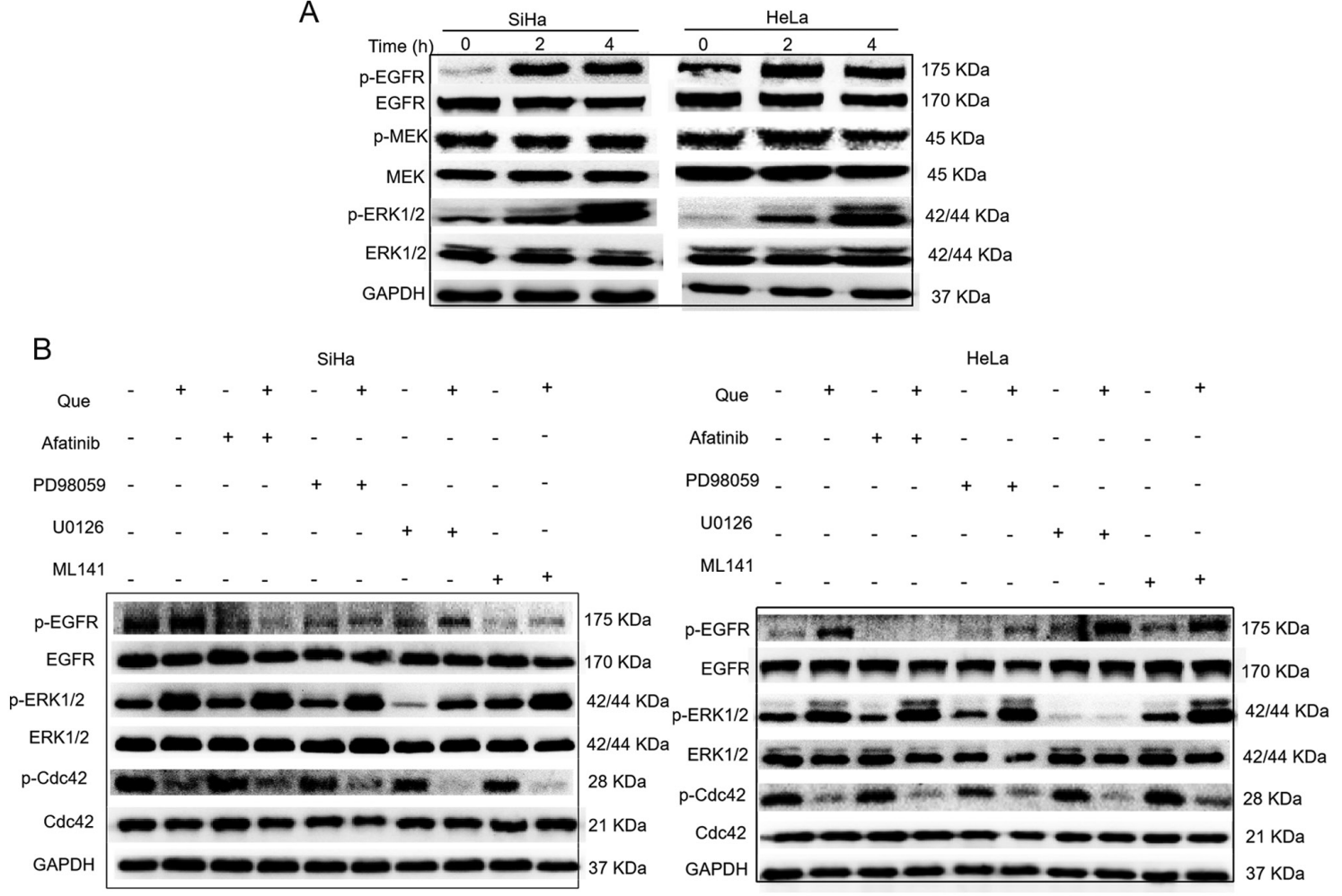

C $\mathrm{SiHa}$

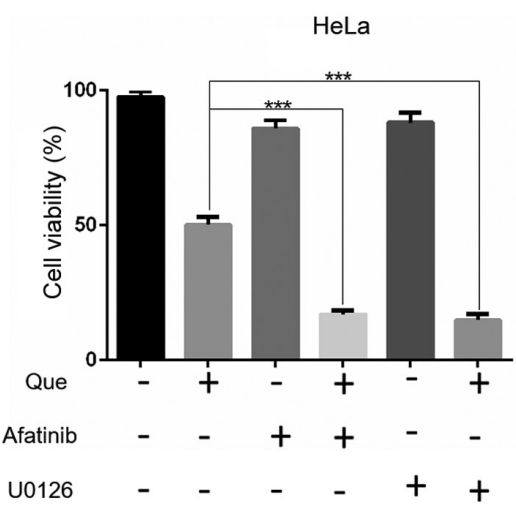

Figure 6. EGFR and ERK exert a protective role in Que-induced anticancer effects. (A) The cells were treated for different times with Que (80 $\mu \mathrm{M})$ and (B) with different combinations of Que and inhibitors. Expression levels of the indicated proteins, which were activated by Que and blocked with the inhibitors, were analyzed using western blot analysis. GAPDH was used as the loading control. (C) The cervical cancer cell lines were pretreated with afatinib (5 $\mu \mathrm{M})$ and U0126 $(10 \mu \mathrm{M})$ for $1 \mathrm{~h}$, then treated with Que $(80 \mu \mathrm{M})$ for $24 \mathrm{~h}$ to detect cell viability using an MTT assay. $\mathrm{n}=3$. ${ }^{* * *} \mathrm{P}<0.001$. Que, quercetin; $\mathrm{p}$, phosphorylated.

been circulated as a commodity in the United States and some European countries $(25,26)$. Nutrigenomics aims to understand how the active ingredients of food directly or indirectly affect the changes in the human genome structure, and to investigate the effects of dietary factors and nutrients on the human genome. In addition, to investigate which chronic or hereditary diseases, such as irritable bowel syndrome, musculoskeletal pain, chronic pelvic pain and dry eye are susceptible to dietary factors, and explore the differences in the sensitivity of healthy humans and diseased patients to different dietary factors based on differences in human genetic polymorphisms (27).

The occurrence of cervical cancer may be associated with the activation of certain proto-oncogenes, such as EGFR, which is widely distributed in mammalian epithelial cells and binds to EGF or TNF $(28,29)$. EGFR is a glycoprotein that belongs to the tyrosine kinase type receptor family and its different phosphorylation sites regulate various downstream signal pathways, such as PI3K/AKT and Ras/Raf/MEK/ERK (30). The current study focused on signaling regulation after activation at Tyr1068. Tyrosine kinase receptor, which is activated by growth factors, binds to growth factor receptor-bound protein 2 (GRB2) directly or indirectly, following which GRB2 recruits the guanylate exchange factor, SOS (Ras/Rac guanine nucleotide exchange factor 1), which is located on the cell membrane adjacent to Ras and a series of cascade amplification reactions occur after Ras is activated $(31,32)$. The transcriptome refers to the collection of all transcripts in a specific type of cell. In other words, it is a snapshot of the expression profile of a cell at a specific time. In the transcriptome, it includes both the familiar messengers that encode proteins (mRNA), non-coding RNA, such as microRNA, which does not code for protein and long non-coding (lnc)RNA, which are newly discovered $(33,34)$. 

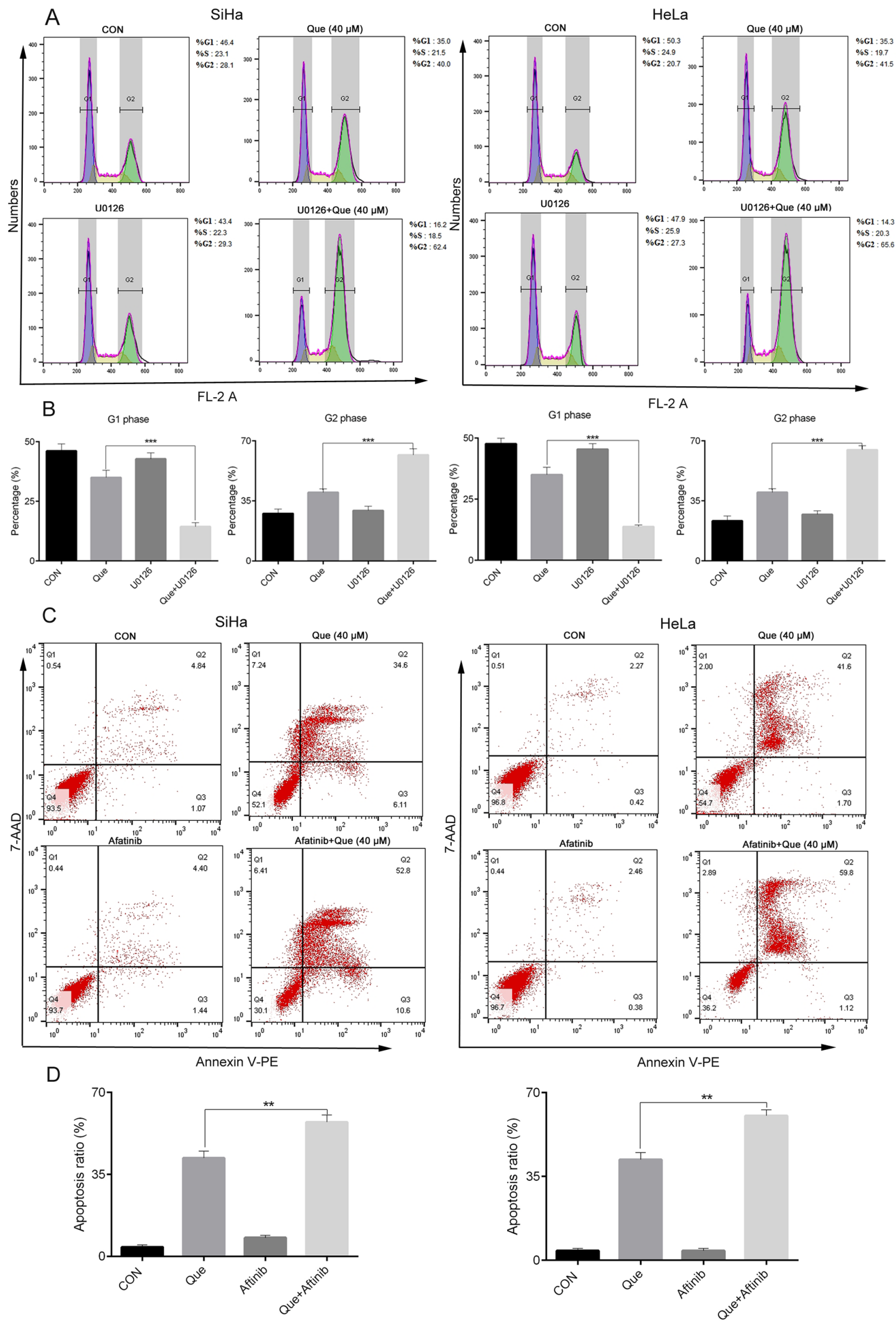

Figure 7. EGFR and ERK protect cervical cancer cells from apoptosis and cell cycle arrest. (A and C) The cervical cancer cell lines were pretreated with afatinib $(5 \mu \mathrm{M})$ and $\mathrm{U} 0126(10 \mu \mathrm{M})$ for $1 \mathrm{~h}$, then treated with Que $(80 \mu \mathrm{M})$ for $24 \mathrm{~h}$ to detect cell viability and apoptosis using FACS assays, or treated with Que $(40 \mu \mathrm{M})$ for $8 \mathrm{~h}$ to evaluate the cell cycle. (B and D) The difference was statistically analyzed. $\mathrm{n}=3$. ${ }^{* * *} \mathrm{P}<0.01,{ }^{* * *} \mathrm{P}<0.001$. Que, quercetin. 


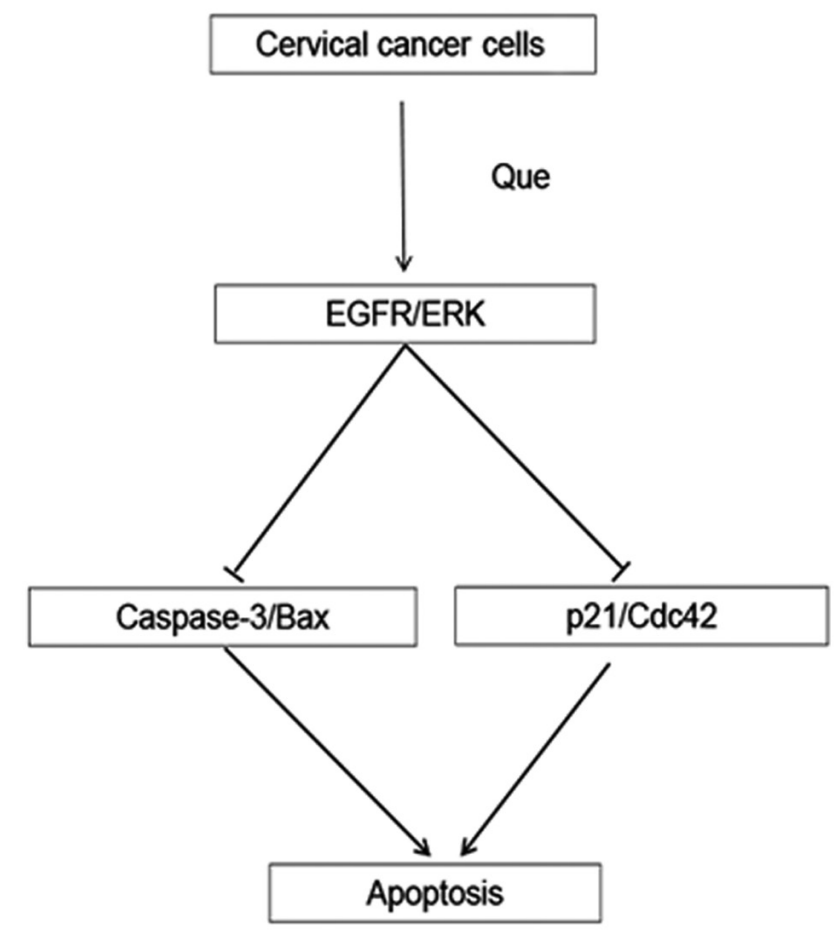

Figure 8. Model of Que-induced antitumor effects in the cervical cancer cell lines. Que leads to the activation of EGFR and ERK kinases, then affects the expression levels of apoptosis-related proteins to resist cytotoxicity. Que, quercetin.

These RNA transcripts combine to regulate a series of important physiological processes, such as cell growth, development and apoptosis (35). After autophosphorylation, EGFR binds directly or indirectly to the GRB2 complex to activate the Ras protein. The activated Ras activates the downstream serine/threonine protein kinase, Raf to phosphorylate ERK-1 and 2. The signal is transmitted to the nucleus, leading to the phosphorylation of transcription factors in the nucleus, starting the transcription of target genes, and ultimately leading to biological effects, such as cell proliferation and proliferation (36). In total, 4 major MAPKs have been identified: ERK1/2, JNK/stress activated protein kinases, p38 MAPK and ERK5 (37).

ERK activation can exert an anti-apoptotic or proapoptotic effects, depending on the stimulation and cell types. ERKs are mainly, but not only, activated by growth factors and participate in mitosis regulation (38). It also transfers to the nucleus and activates transcription factors to produce corresponding biological effects directly after being activated (39). The activation of Raf is not completely dependent on Ras and ERK can also be activated by other factors, such as SOS and ILs, thus forming a complex network regulatory structure (40). The present results suggested that Que activated ERK independent of EGFR, and published studies have confirmed that receptor tyrosine kinases, $\mathrm{G}$ protein-coupled receptors and some cytokine receptors, such as Ras, Raf and MEK can all activate the ERK signal transduction pathway (41,42). Deng et al (43) reported that Que induced human breast cell apoptosis by inhibiting ERK, high-affinity potassium transporter and survivin. In addition, Kim et al (44) observed that Que promoted cycle arrest and apoptosis of melanoma cells by increasing the ratio of $\mathrm{Bax} / \mathrm{Bcl}-2$, and inhibited the PI3K/AKT and ERK/JNK pathways involved in cell prolif- eration and signal transduction, while Balakrishnan et al (45) revealed that Que induced MCF-7 breast cancer cell apoptosis by activating AMP-activated protein kinase, thereby inhibiting the expression of cyclooxygenase- 2 .

EdU is a thymidine analogue and the alkyne group attached to this factor is rare in natural compounds. This group can replace thymine into a synthetic DNA molecule during DNA replication (46). Based on the specific reaction between Apollo fluorescent dye and EdU, DNA replication activity can be directly and accurately detected (47). The present MTT and EdU assay results demonstrated that Que had a notable inhibitory activity on the viability of cervical cancer cells, while flow cytometry detection identified that Que significantly promoted $\mathrm{G}_{2} / \mathrm{M}$ phase arrest and apoptosis. Furthermore, the wound healing and Transwell assays suggested that Que inhibited cellular migration and invasion.

Apoptosis and cell cycle processes are strictly governed by multiple genes, such as Bcl-2, caspase and the CDK family (48). Caspase- 3 is one of the most important enzymes, which is a terminal splicing factor in the process of cell apoptosis and plays an irreplaceable role in this process. The main substrate of caspase- 3 is poly (ADP-ribose) polymerase 1, and caspase-3 can be cleaved by this factor, leading to an inhibition of DNA repair and initiation of degradation $(49,50)$. Cdc42 is a member of the $\varrho$ family, and serves an important role in the establishment and maintenance of epithelial cell polarity by regulating the formation of microtubules and microfilament skeletons and intercellular connection (51). It was found that the protein expression level of p-Cdc42 was markedly decreased following the addition of Que; however, its expression after $4 \mathrm{~h}$ of Que treatment was slightly increased compared with that after $2 \mathrm{~h}$. This may be caused by the negative feedback regulation mechanism, which requires further investigation. p21 was first discovered as a downstream gene of p53, and subsequently, scientists have conducted numerous studies examining p21 and have shown that it is an important cell cycle government target $(52,53)$. p21 is involved in the process of cell proliferation, differentiation, senescence and death (54). At the same time, it is associated with the occurrence of tumors and serves a role in the physiological and pathological processes. Previous studies have confirmed that $\mathrm{p} 21$ can form a complex with cyclin D/CDK to block the cell cycle in G1 phase and it can also interact with proliferating cell nuclear antigen (PCNA) via the C-terminus to block the activity of PCNA-activated DNA polymerase, thereby inhibiting DNA synthesis and arresting the cell cycle $(55,56)$.

MAPK can transduce extracellular signals into the nucleus via a 3-level kinase cascade (MAPKKK>MAPKK $>$ MAPK), thereby regulating cell proliferation, differentiation, apoptosis, inflammatory response and other biological behaviors, such as antitumor effects (57). The RAS/RAF/MEK/ERK axis has been the mostly widely investigated of the aforementioned cascades. The present study analyzed the negative regulatory effect of the activation of EGFR and ERK when the cervical cancer cell lines were treated with Que, as both EGFR and ERK inhibitors enhanced the Que-induced anticancer effects. Que activates EGFR and ERK and inhibits the activity of related kinases, indicating that the activation of EGFR and ERK resists the effect of Que-mediated apoptosis in cervical cancer cells (Fig. 8).

In conclusion, the present study conducted network pharmacology analysis, and the results demonstrated that Que may be 
one of the active components of SH. Furthermore, Que notably inhibited the viability of cervical cancer cells, and induced $\mathrm{G}_{2} / \mathrm{M}$ arrest and apoptosis. EGFR and ERK activation was associated with the resistance to Que-induced anticancer activities, as both EGFR and ERK inhibitors enhanced the Que-induced anticancer effects. Thus, it would be important to examine the combination of Que and EGFR inhibitors in the treatment of cervical cancer. Collectively, the present study suggested that EGFR and ERK activation served a protective role in Que-induced anticancer activities in cervical cancer in vitro. If Que is used for clinical application, the combination of afatinib may enhance the antitumor effect of Que one day, but this topic is based on the conclusions obtained from in vitro cell experiments and in vivo animal experiments have not been conducted, therefore further investigation is required to confirm the conclusions.

\section{Acknowledgements}

Not applicable.

\section{Funding}

This study was supported in part by the National Natural Science Foundation of China (grant nos. 81560429, 81602545 and 81760519) and the Yunnan Natural Science Foundation of China [grant nos. 2017FF116 (-023) and 2019FF002 (-011)]

\section{Availability of data and materials}

The datasets used and/or analyzed during the current study are available from the corresponding author on reasonable request.

\section{Authors' contributions}

XC completed the experiments. PX and LG made substantial contributions to conception and design. HZ, XS, LG, XZ, JW and $\mathrm{PH}$ analyzed the data, drafted the manuscript and revised it critically for important intellectual content. RS and QZ approved the final version of the manuscript, confirmed the authenticity of the raw data generated during the study, and guided and planned the study. All authors read and approved the final manuscript.

\section{Ethics approval and consent to participate}

Not applicable.

\section{Patient consent for publication}

Not applicable.

\section{Competing interests}

The authors declare that they have no competing interests.

\section{References}

1. Woo S, Atun R, Ward ZJ, Scott AM, Hricak H and Vargas HA: Diagnostic performance of conventional and advanced imaging modalities for assessing newly diagnosed cervical cancer: Systematic review and meta-analysis. Eur Radiol 30: 5560-5577, 2020.
2. Tran KN, Park Y, Kim BW, Oh JK and Ki M: Incidence and mortality of cervical cancer in Vietnam and Korea (1999-2017). Epidemiol Health 42: e2020075, 2020.

3. Benitez-Restrepo CC, Arias-Ortiz NE and Arboleda-Ruiz WA: Cervical cancer incidence and patient survival in Manizales, Colombia, 2008-2012. Rev Peru Med Exp Salud Publica 37: 438-445, 2020 (In Spanish, English).

4. D'Alton P, Craddock F, Bergin N and Lynch J: Exploring the lived experience of partners of women impacted by cervical cancer and the CervicalCheck screening failure in Ireland. Psychooncology: Jun 7, 2021 (Epub ahead of print).

5. Malikova H, Burghardtova M, Fejfarova K, Nadova $K$ and Weichet J: Advanced cervical cancer in young women: Imaging study of late and very late radiation-related side effects after successful treatment by combined radiotherapy. Quant Imaging Med Surg 11: 21-31, 2021.

6. Zhang FY, Li JJ, Zhou Y and Xu XY: Review for sedative and hypnotic mechanism of sedative traditional Chinese medicine and relative active components on neurotransmitters. Zhongguo Zhongyao Zazhi 41: 4320-4327, 2016 (In Chinese).

7. Qian C, Kuang M and Wang Y: Effect of qianghuo erhuang decoction on $\mathrm{T}$ regulatory and $\mathrm{T}$ Helper 17 cells in treatment of adjuvant-induced arthritis in rats. Sci Rep 7: 17198, 2017.

8. Chen H, Feng X, GaoL, Mickymaray S, Paramasivam A, Abdulaziz Alfaiz F, Almasmoum HA, Ghaith MM, Almaimani RA and Aziz Ibrahim IA: Inhibiting the PI3K/AKT/mTOR signalling pathway with copper oxide nanoparticles from Houttuynia cordata plant: Attenuating the proliferation of cervical cancer cells. Artif Cells Nanomed Biotechnol 49: 240-249, 2021.

9. Zeng Y, Liu J, Zhang Q, Qin X, Li Z, Sun G and Jin S: The traditional uses, phytochemistry and pharmacology of Sarcandra glabra (Thunb.) Nakai, a Chinese herb with potential for development: Review. Front Pharmacol 12: 652926, 2021. Review.

10. Zhang Y, Yuan T, Li Y, Wu N and Dai X: Network pharmacology analysis of the mechanisms of compound Herba Sarcandrae (Fufang Zhongjiefeng) aerosol in chronic pharyngitis treatment. Drug Des Devel Ther 15: 2783-2803, 2021.

11. Guo X, Shen L, Tong Y, Zhang J, Wu G, He Q, Yu S, Ye X, Zou L, Zhang Z, et al: Antitumor activity of caffeic acid 3,4-dihydroxyphenethyl ester and its pharmacokinetic and metabolic properties. Phytomedicine 20: 904-912, 2013.

12. Trusov NV, Apryatin SA, Shipelin VA and Gmoshinski IV: Full transcriptome analysis of gene expression in liver of mice in a comparative study of quercetin efficiency on two obesity models. Probl Endokrinol (Mosk) 66: 31-47, 2020 (In Russian).

13. Flater D: A system of quantities from software metrology. Measurement (Lond) 168: 2021. doi: 10.1016/j. measurement.2020.108435.

14. Mokhtari Sangdehi SR, Hajizadeh Moghaddam A and Ranjbar M: Anti-apoptotic effect of silymarin-loaded chitosan nanoparticles on hippocampal caspase- 3 and $\mathrm{Bcl}-2$ expression following cerebral ischemia/reperfusion injury. Int J Neurosci: Jan 21, 2021 (Epub ahead of print).

15. Zhang X, Huang R, Gopalakrishnan S, Cao-Milán R and Rotello VM: Bioorthogonal nanozymes: Progress towards therapeutic applications. Trends Chem 1: 90-98, 2019.

16. Luckett R and Feldman S: Will HPV vaccination affect cervical cancer morbidity and mortality world-wide? Hum Vaccin Immunother 12: 1373-1374, 2016.

17. Dehelean CA, Marcovici I, Soica C, Mioc M, Coricovac D, Iurciuc S, Cretu OM and Pinzaru I: Plant-derived anticancer compounds as new perspectives in drug discovery and alternative therapy. Molecules 26: 26, 2021.

18. Mohsenpour H, Pesce M, Patruno A, Bahrami A, Pour PM and Farzaei MH: A review of plant extracts and plant-derived natural compounds in the prevention/treatment of neonatal hypoxic-ischemic brain injury. Int J Mol Sci 22: 22, 2021.

19. Yoo S, Yang HC, Lee S, Shin J, Min S, Lee E, Song M and Lee D: A deep learning-based approach for identifying the medicinal uses of plant-derived natural compounds. Front Pharmacol 11: $584875,2020$.

20. Vu DL,Žabčíková S, Červenka L, Ertek B and Dilgin Y: Sensitive voltammetric determination of natural flavonoid quercetin on a disposable graphite lead. Food Technol Biotechnol 53: 379-384, 2015.

21. Harwood M, Danielewska-Nikiel B, Borzelleca JF, Flamm GW, Williams GM and Lines TC: A critical review of the data related to the safety of quercetin and lack of evidence of in vivo toxicity, including lack of genotoxic/carcinogenic properties. Food Chem Toxicol 45: 2179-2205, 2007. 
22. Elmowafy M, Musa A, Alnusaire TS, et al: Olive Oil/Pluronic Oleogels for Skin Delivery of Quercetin: In Vitro Characterization and Ex Vivo Skin Permeability. Polymers (Basel) 13: 2021.

23. Kim JM, Seo SW, Han DG, Yun H and Yoon IS: Assessment of metabolic interaction between repaglinide and quercetin via mixed inhibition in the liver: In vitro and in vivo. Pharmaceutics May 23, 2021 (Epub ahead of print).

24. Boulton DW, Walle UK and Walle T: Fate of the flavonoid quercetin in human cell lines: Chemical instability and metabolism. J Pharm Pharmacol 51: 353-359, 1999.

25. Ferry DR, Smith A, Malkhandi J, Fyfe DW, deTakats PG, Anderson D, Baker J and Kerr DJ: Phase I clinical trial of the flavonoid quercetin: Pharmacokinetics and evidence for in vivo tyrosine kinase inhibition. Clin Cancer Res 2: 659-668, 1996

26. Chalet C, Hollebrands B, Duchateau GS and Augustijns P: Intestinal phase-II metabolism of quercetin in HT29 cells, 3D human intestinal tissues and in healthy volunteers: A qualitative comparison using LC-IMS-MS and LC-HRMS. Xenobiotica 49: 945-952, 2019.

27. Rashedi J, Ghorbanihaghjo A, Asgharzadeh M and Baradaran B Chitosan and quercetin: Potential hand in hand encountering tumors in oral delivery system. Curr Pharm Des 25: 3074-3086, 2019.

28. Peng Z, Wang Q, Zhang Y, He J and Zheng J: EBP50 interacts with EGFR and regulates EGFR signaling to affect the prognosis of cervical cancer patients. Int J Oncol 49: 1737-1745, 2016.

29. Zhang W, Gao Y, Jiang Y, Ping L, Cheng $\mathrm{H}$ and Zhang J: EGFR promoter methylation detection in cervical cancer by a hybridization-fluorescence polarization assay. Diagn Mol Pathol 22: 102-106, 2013

30. Hartman Z, Geldenhuys WJ and Agazie YM: A specific amino acid context in EGFR and HER 2 phosphorylation sites enables selective binding to the active site of Src homology phosphatase 2 (SHP2). J Biol Chem 295: 3563-3575, 2020.

31. Guerrero C, Pesce L, Lecuona E, Ridge KM and Sznajder JI: Dopamine activates ERKs in alveolar epithelial cells via Ras-PKC-dependent and Grb2/Sos-independent mechanisms. Am J Physiol Lung Cell Mol Physiol 282: L1099-L1107, 2002.

32. Liu Y, Shi QF, Ye YC, Tashiro S, Onodera S and Ikejima T: Activated $\mathrm{O}_{2}(\bullet-)$ and $\mathrm{H}_{2} \mathrm{O}_{2}$ mediated cell survival in SU11274-treated non-small-cell lung cancer A549 cells via c-Met-PI3K-Akt and c-Met-Grb2/SOS-Ras-p38 pathways. J Pharmacol Sci 119: 150-159, 2012.

33. Viñas JL, Spence M, Porter CJ, Douvris A, Gutsol A Zimpelmann JA, Campbell PA and Burns KD micro-RNA-486-5p protects against kidney ischemic injury and modifies the apoptotic transcriptome in proximal tubules. Kidney Int: Jun 26, 2021 (Epub ahead of print).

34. Xu Z, Shi X, Bao M, Song X, Zhang Y, Wang H, Xie H, Mao F, Wang $\mathrm{S}$, Jin $\mathrm{H}$, et al: Transcriptome-wide analysis of RNA m6A methylation and gene expression changes among two arabidopsis ecotypes and their reciprocal hybrids. Front Plant Sci 12: 685189, 2021

35. Toki MI, Carvajal-Hausdorf DE, Altan M, McLaughlin J, Henick B, Schalper KA, Syrigos KN and Rimm DL: EGFR-GRB2 protein colocalization is a prognostic factor unrelated to overall EGFR expression or EGFR mutation in lung adenocarcinoma. J Thorac Oncol 11: 1901-1911, 2016.

36. Ouyang L, Chen Y, Wang XY, Lu RF, Zhang SY, Tian M, Xie T, Liu B and He G: Polygonatum odoratum lectin induces apoptosis and autophagy via targeting EGFR-mediated Ras-Raf-MEK-ERK pathway in human MCF-7 breast cancer cells. Phytomedicine 21: $1658-1665,2014$

37. Correia I, Wilson D, Hube B and Pla J: Characterization of a Candida albicans mutant defective in all MAPKs highlights the major role of Hog1 in the MAPK signaling network. J Fungi (Basel) 6: 6, 2020 .

38. Dalton GD and Howlett AC: Cannabinoid CB1 receptors transactivate multiple receptor tyrosine kinases and regulate serine/threonine kinases to activate ERK in neuronal cells. Br J Pharmacol 165: 2497-2511, 2012.

39. Tsarouhas V, Yao L and Samakovlis C: Src kinases and ERK activate distinct responses to Stitcher receptor tyrosine kinase signaling during wound healing in Drosophila. J Cell Sci 127 $1829-1839,2014$

40. Qi ZH, Xu HX, Zhang SR, Xu JZ, Li S, Gao HL, Jin W, Wang WQ, Wu CT, Ni QX, et al: RIPK4/PEBP1 axis promotes pancreatic cancer cell migration and invasion by activating RAF1/MEK/ ERK signaling. Int J Oncol 52: 1105-1116, 2018.
41. Yu X, Stallone JN, Heaps CL and Han G: The activation of G protein-coupled estrogen receptor induces relaxation via cAMP as well as potentiates contraction via EGFR transactivation in porcine coronary arteries. PLoS One 13: e0191418, 2018.

42. Mulner-Lorillon O, Chassé H, Morales J, Bellé R and Cormier P: MAPK/ERK activity is required for the successful progression of mitosis in sea urchin embryos. Dev Biol 421: 194-203, 2017.

43. Deng XH, Song HY, Zhou YF, Yuan GY and Zheng FJ: Effects of quercetin on the proliferation of breast cancer cells and expression of survivin in vitro. Exp Ther Med 6: 1155-1158, 2013

44. Kim SH, Yoo ES, Woo JS, Han SH, Lee JH, Jung SH, Kim HJ and Jung JY: Antitumor and apoptotic effects of quercetin on human melanoma cells involving JNK/P38 MAPK signaling activation. Eur J Pharmacol 860: 172568, 2019.

45. Balakrishnan S, Mukherjee S, Das S, Bhat FA, Raja Singh P, Patra CR and Arunakaran J: Gold nanoparticles-conjugated quercetin induces apoptosis via inhibition of EGFR/PI3K/ Akt-mediated pathway in breast cancer cell lines (MCF-7 and MDA-MB-231). Cell Biochem Funct 35: 217-231, 2017.

46. Mina U, Smiti K and Yadav P: Thermotolerant wheat cultivar (Triticum aestivum L. var. WR544) response to ozone, EDU, and particulate matter interactive exposure. Environ Monit Assess 193: 318,2021

47. Troth EV and Kyle DE: EdU incorporation to assess cell proliferation and drug susceptibility in Naegleria fowleri. Antimicrob Agents Chemother 65: e0001721, 2021.

48. Wu LW, Chiang YM, Chuang HC, Lo CP, Yang KY, Wang SY and Shyur LF: A novel polyacetylene significantly inhibits angiogenesis and promotes apoptosis in human endothelial cells through activation of the CDK inhibitors and caspase-7. Planta Med 73: 655-661, 2007.

49. Xu P, Cai X, Zhang W, Li Y, Qiu P, Lu D and He X: Flavonoids of Rosa roxburghii Tratt exhibit radioprotection and anti-apoptosis properties via the $\mathrm{Bcl}-2(\mathrm{Ca}(2+)) /$ Caspase-3/PARP-1 pathway. Apoptosis 21: 1125-1143, 2016.

50. Napso T and Fares F: Zebularine induces prolonged apoptosis effects via the caspase-3/PARP pathway in head and neck cancer cells. Int J Oncol 44: 1971-1979, 2014

51. Ikehata M, Yamada A, Fujita K, Yoshida Y, Kato T, Sakashita A, Ogata H, Iijima T, Kuroda M, Chikazu D, et al: Cooperation of Rho family proteins Rac1 and Cdc42 in cartilage development and calcified tissue formation. Biochem Biophys Res Commun 500: 525-529, 2018.

52. Sha JY, Li JH, Zhou YD, Yang JY, Liu W, Jiang S, Wang YP, Zhang R, Di P and Li W: The p53/p21/p16 and PI3K/Akt signaling pathways are involved in the ameliorative effects of maltol on D-galactose-induced liver and kidney aging and injury. Phytother Res ptr.7142, 2021.

53. Costa BP, Nassr MT, Diz FM, Fernandes KHA, Antunes GL, Grun LK, Barbé-Tuana FM, Nunes FB, Branchini G and de Oliveira JR: Methoxyeugenol regulates the p53/p21 pathway and suppresses human endometrial cancer cell proliferation. J Ethnopharmacol 267: 113645, 2021.

54. Zeng R: Expression of p53, p21, PCNA and COX-2 and its relationship with recurrence in the early-stage laryngeal cancer with negative surgical margin. Lin Chung Er Bi Yan Hou Tou Jing Wai Ke Za Zhi 30: 349-352, 356, 2016 (In Chinese).

55. Chiappara G, Gjomarkaj M, Sciarrino S, Vitulo P, Pipitone L and Pace E: Altered expression of $\mathrm{p} 21$, activated caspase-3, and PCNA in bronchiolar epithelium of smokers with and without chronic obstructive pulmonary disease. Exp Lung Res 40: 343-353, 2014.

56. Li P, Liu X, Hao Z, Jia Y, Zhao X, Xie D, Dong J and Zeng F: Dual Repressive Function by Cip1, a Budding Yeast Analog of p21, in Cell-Cycle START Regulation. Front Microbiol 11: 1623, 2020.

57. Avkiran $M$ and Marber MS: Feeling the stress: MAPKKK-MAPKK-MAPK signaling cascades in heart failure. J Mol Cell Cardiol 48: 283-285, 2010.

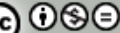

This work is licensed under a Creative Commons Attribution-NonCommercial-NoDerivatives 4.0 International (CC BY-NC-ND 4.0) License. 